NBER WORKING PAPER SERIES

\title{
EFFECTS OF TITLE IX AND SPORTS PARTICIPATION ON GIRLS' PHYSICAL ACTIVITY AND WEIGHT
}

\author{
Robert Kaestner \\ $\mathrm{Xin} \mathrm{Xu}$ \\ Working Paper 12113 \\ http://www.nber.org/papers/w12113 \\ NATIONAL BUREAU OF ECONOMIC RESEARCH \\ 1050 Massachusetts Avenue \\ Cambridge, MA 02138 \\ March 2006
}

This research was partially supported by grants from the Robert Wood Johnson Foundation and from the Chicago Center for Excellence in Health Promotion Economics of the University of Chicago and University of Illinois at Chicago. The views expressed herein are those of the author(s) and do not necessarily reflect the views of the National Bureau of Economic Research.

(C)2006 by Robert Kaestner and Xin Xu. All rights reserved. Short sections of text, not to exceed two paragraphs, may be quoted without explicit permission provided that full credit, including $\odot$ notice, is given to the source. 
Effects of Title IX and Sports Participation on Girls' Physical Activity and Weight

Robert Kaestner and Xin Xu

NBER Working Paper No. 12113

March 2006, Revised June 2006

JEL No. I12, I18

\begin{abstract}
of adolescent girls.
Robert Kaestner

Department of Economics

Institute of Government and Public Affairs

University of Illinois at Chicago

815 West Van Buren Street, Suite 525

Chicago, IL 60607

and NBER

$\underline{\text { kaestner@uic.edu }}$

$\mathrm{Xin} \mathrm{Xu}$

Graduate College (MC 192)

601 South Morgan

Room 606 University Hall

Chicago, IL 60607-7106

xxu11@uic.edu
\end{abstract}

ABSTRACT

In this study, we examined the association between girls' participation in high school sports and the physical activity, weight, body mass and body composition of adolescent females during the 1970s when girls' sports participation was dramatically increasing as a result of Title IX. We found that increases in girls' participation in high school sports, a proxy for expanded athletic opportunities for adolescent females, were associated with an increase in physical activity and an improvement in weight and body mass among girls. In contrast, adolescent boys experienced a decline in physical activity and an increase in weight and body mass during the period when girls' athletic opportunities were expanding. Taken together, these results strongly suggest that Title IX and the increase in athletic opportunities among adolescent females it engendered had a beneficial effect on the health 


\section{Introduction}

The 1996 Surgeon General's Report on Physical Activity and Health (USDHHS 1996) is an exhaustive review of the effects of physical activity on health. It concludes that there is compelling evidence that people of all ages and of both genders benefit from physical activity, and it recommends 30 minutes of regular physical activity (e.g., brisk walking, social dancing, volleyball) on most days for both children and adults. A more recent study from the Institute of Medicine (2002) goes even further, recommending an hour of physical activity per day.

The Surgeon General's study also reports the following: that most Americans are not regularly physically active; that $25 \%$ of American adults are not active at all; and that half of American youths between the ages of 12 and 21 are not vigorously active on a regular basis. Notably, at all ages, women are less active than men. The relatively high rate of physical inactivity among Americans is an important social problem. Indeed, physical activity is one of the major public health concerns listed in the Healthy People 2010 (USDHHS 2000) report, which has an objective to increase physical activity, and which identifies women as a group of particular concern.

To increase physical activity of children and adults, the 1996 Surgeon General's report recommends the expansion of school-based interventions.

"School-based interventions for youth are particularly promising, not only for their potential scope-almost all young people between the ages of 6 and 16 years attend school—but also for their potential impact. Nearly half of young people 12 to 21 years of age are not vigorously active; moreover, physical activity declines during adolescence. Childhood and adolescence may thus be pivotal times for preventing sedentary behavior among adults by maintaining the habit of physical activity throughout the school years." (USDHHS 1996, p. 12)

A similar recommendation is made in a report by The President's Council on Physical Fitness and Sports (1997) entitled, "Physical Activity \& Sports in the Lives of Girls."

"Specific mechanisms which enhance girls' opportunities to be physically active must be developed and supported. Recreational, school-based physical education and sport programs are ideal ways to facilitate both health-related fitness and the acquisition of fundamental motor skills for a lifetime of activity." (The President's Council on Physical Fitness and Sports 1997, p. xv)

Finally, from the Centers for Disease Control (CDC), we have the following:

"Children and adolescents are more physically active than adults, but participation in physical activity declines in adolescence. School and community programs have the potential to help children and adolescents establish lifelong, healthy physical activity patterns." (CDC 1997, p. 2) 
One of the most important justifications of these recommendations to increase youth physical activity through school-based programs is improved body composition (ratio of fat to lean mass) and reduced obesity. There is a widespread belief that school-based, physical activity programs will have a beneficial effect on child and adolescent obesity. Moreover, note that all of the recommendations imply that youth programs will have lifetime effects, which is consistent with the evidence that childhood obesity is strongly associated with adult obesity (Serdula et al. 1993; Lake et al. 1997; McTigue et al. 2002; Whitaker et al. 1998). So the potential benefits of greater youth physical activity are large. Yet, there is little direct evidence to support the link between youth physical activity and obesity, or body composition (Cawley et al. 2005). Intervention studies have demonstrated that physical activity and exercise can help control weight, but observational studies of the relationship between physical activity and child obesity have reported inconsistent findings (Stefanick 1993; Slattery et al.1992; USDHHS 1996; Kimm et al. 2005).

Arguably the most important school-based intervention to increase physical activity was Title IX of the Education Amendments of 1972. This landmark legislation led to a dramatic increase in girls' sports participation after its passage in 1972. Between the 1970-71 and 1977-78 academic years, the number of girls participating in high school sports increased over 600\%, from 294,015 to 2,083,040 (National Federation of State High School Associations, 2001). In the same period, the rate of girls' participation in high school sports increased from approximately five percent to 26 percent (see Figure 1). Title IX has also been credited with spurring girls' participation in community sports programs. In contrast, Title IX had almost no effect on boys. Between 1970-71 and 1977-78, the number of boys participating in high school sports increased approximately $20 \%$ and their rate of participation in sports hardly changed (see Figure 1).

Title IX and the unprecedented increase in girls' sports participation that resulted provides a unique opportunity to study the effect of school-based interventions targeted at increasing physical activity on adolescent female obesity. The primary goal of the proposed research is to obtain estimates of the effect of the dramatic increase in girls' participation in high school sports, as a result of Title IX legislation, on the physical activity, body mass and body composition of adolescent women. The proposed research, because it will make use of a plausibly exogenous change in physical activity, will provide perhaps the most credible evidence to date 
on the effect of physical activity on youth obesity. Previous researchers have not exploited this dramatic change in girls' sports participation caused by Title IX to investigate the consequences of such participation. More importantly, the formulation of current policy and recommendations to expand school-based interventions to increase physical activity has not benefited from knowledge about the health consequences of Title IX—the largest expansion in school-based interventions in history. While Title IX has left an indelible mark on our society, and its success in creating equal opportunities for women widely celebrated, its effect on physical activity and health remain unknown. Here we begin to address this shortfall in knowledge.

\section{What is Title IX and Did it Affect Sports Particpation?}

"No person in the United States shall, on the basis of sex, be excluded from participation in, be denied the benefits of, or be subjected to discrimination under any education program or activity receiving Federal financial assistance." (US Department of Education 2000)

So begins Title IX of the Education Amendments of 1972 that took effect in June of 1972. The language of Title IX is broad and covers all activities sponsored by educational institutions. Programs and activities which receive funds from the Department of Education must operate in a nondiscriminatory manner. These programs and activities include: admissions, recruitment, financial aid, academic programs, student treatment and services, counseling and guidance, discipline, classroom assignment, grading, vocational education, recreation, physical education, athletics, housing and employment.

Title IX enforcement is the responsibility of the Office of Civil Rights of the Department of Education. Enforcement is governed by regulations issued by the Department of Health, Education, and Welfare (predecessor to the Department of Education), which became effective July 21, 1975. The regulations established a three year transition period to give institutions time to comply with its equal athletic opportunity requirements. That transition period expired on July 21, 1978. Compliance with Title IX involved a selfevaluation of current practices and remedial steps to eliminate the effects of any discrimination.

Institutions could also take affirmative action to address limited participation by persons of a particular sex (Department of Education 1975). 
While Title IX affected many programs and employment at educational institutions, arguably its greatest impact was on sports participation. Between 1970-71 and 1977-78, the number of girls participating in high school sports increased over $600 \%$, and the rate of girls' participation in high school sports increased from five percent to 26 percent (Figure 1, National Federation of State High School Associations 2002; Stevenson 2000; Gavora 2002). However, girls' sports participation was increasing prior to Title IX (Gavora 2002; Staffo 1980; Riley 1976) and the data on sports participation is relatively crude and subject to substantial error (see below). Moreover, as described above, Title IX was implemented gradually with federal regulations not issued until 1975, compliance not required until 1978 and little enforcement teeth until 1980 (Gavora 2002; Women's Sports Foundation 2001).

Nevertheless, given the large increase in girls' sports participation that occurred subsequent to passage of Title IX and which more or less ended at the time of mandated compliance in 1978, it is difficult to argue that the law had no effect on girls' sports participation, and evidence suggests that it had a substantial effect. Again, Gavora (2002), a strong critic of Title IX, concludes that Title IX clearly intensified the upward trend in girls' sports participation. Data on girls' sports participation prior to 1970 is sparse, but the information that does exist indicates a significant break in the trend line after passage of Title IX (Riley 1976; Staffo 1980). Further, there is abundant evidence that school administrators responsible for sports were cognizant of the burden of Title IX and responded accordingly (Pottker and Fishel 1976; Riley 1976; Staffo 1980; American Friends Service Committee 1977). In fact, the Department of Health Education and Welfare (HEW) worked with the American Association of School Administrators and sponsored many regional and area conferences on compliance with Title IX (Riley 1976; American Friends Service Committee 1977; Craig 1977). And Gavora (2002) reports that the Department of Health, Education and Welfare (HEW) was "flooded" with complaints from school administrators struggling to comply with Title IX regulations issued in 1975.

Did Title IX affect boys' sports participation? Clearly, recent court cases and media attention suggest that at the college level, male athletic opportunities may have been diminished by Title IX, although supporters of the law refute this claim and all of these court cases have been brought since 1988. But evidence of similar problems at the elementary and secondary levels is virtually non-existent during the 1970s and 1980s. And a review of the legal cases from the 1990s related to elementary and secondary schools that were listed on the 
Gender Equity in Sports website (http://bailiwick.lib.uiowa.edu/ge/) found no cases at the elementary or secondary school level in which males complained about a loss of opportunities. Finally, the aspect of Title IX that arguably had the greatest potential of adversely affecting boys was the 1979 Title IX Athletics Policy Interpretation rule issued by the Department of Education that specified that compliance with Title IX required that the proportion of girls among sports participants must be the same as the proportion of girls among the student body. This rule may provide a strong incentive to reduce boys' sports opportunities, but importantly, it was issued in the last year of our analysis. Indeed, prior to 1980, compliance with Title IX was not vigorously enforced and the law itself explicitly forbade the use of quotas (Gavora 2002):

"Nothing contained in ... this section shall be interpreted to require any educational institution to grant preferential or disparate treatment to members of one sex on account of an imbalance which may exist with respect to the total number or percentage of persons of that sex participating in or receiving the benefits of any federally supported program or activity in comparison with the total number or percentage of persons of that sex in any community, state, section or other area." (US Department of Education 2000)

Data show that subsequent to Title IX, there was no decrease in boys' sports participation. Between 1970-71 and 1977-78, the number of boys participating in high school sports increased approximately $20 \%$ and their rate of participation in sports decreased just two percentage points with most of this decrease occurring between 1977 and 1978, the year before compliance became mandatory and two years prior to the issuance of 1979 Title IX Athletics Policy Interpretation rule issued by the Department of Education (Figure 1, National Federation of State High School Associations, 2001; Stevenson 2000). ${ }^{1}$ Evidence in Staffo (1980), who surveyed New York State high schools in the late 1970s is consistent with the aggregate data and supports the notion that Title IX did not adversely affect athletic opportunities for boys at the high school level.

The decrease in boys' (and girls') sports participation observed in Figure 1 merits further discussion. We do not believe it represents an adverse effect of Title IX on boys. First, the drop is in large part a result of implausibly large decreases in sports participation rates that is most likely a result of reporting error. For example, Arkansas, Delaware, Wisconsin, North Dakota and Ohio reported decreases in boys' sports participation of 25 percent or more. And in all but one of these states, girls' sports participation also falls significantly, by 12 or more percent. Indeed, if we rank states by the percentage change in both boys' and girls'

\footnotetext{
${ }^{1}$ The trend in boys' sports participation may have been different if Title IX had not been implemented. That is, we do not know the counterfactual - what boys' participation would have been in the absence of Title IX.
} 
sports participation between 1977 and 1978, the correlation coefficient is quite large -0.70 , which suggests a reporting error more than an effect of Title IX. If Title IX improved opportunities for girls at the expense of boys, the rank correlation would be negative or have a small positive value, not a large value like 0.70 . A regression of boys' sports participation on girls' sports participation yields a positive coefficient.

To summarize, while it is true that athletic opportunities for women were expanding prior to Title IX, it appears that there was a significant (exogenous) increase in girls' sports participation subsequent to passage of the law that continued until compliance with the law was mandated in 1978. Indeed, both girls' and boys' sports participation remains relatively flat for the next ten years (Gavora 2002; National Federation of State High School Associations, 2001). In addition, information available leads us to conclude that Title IX did not reduce athletic opportunities for boys during the period we study. In fact, the literature during this period is quite consistent in stating that elementary and secondary schools had been too slow to provide opportunities for girls, and that Title IX enforcement had been too weak. There is no mention of reduced opportunities for boys. And what data is available does not suggest diminished opportunities for boys.

\section{Causal Pathways}

The publicity surrounding the Surgeon General's report on the health benefits of physical activity and the near universal acceptance of its findings suggest that youth sports participation and physical activity would yield large health benefits for adolescents. Surprisingly, there is little evidence supporting this position. Indeed, according to Rowland (1996), “... regular exercise and sports participation should not be expected to improve the well-being of the general population of children and adolescents (p. 154)." Rowland (1996) notes that the primary mortality risks for children and adolescents are accidents, cancers, congenital abnormalities, and homicides — causes that can not be positively affected by physical activity. Further, physical activity and sports participation are not likely to reduce the rate or severity of infectious disease. One obvious adverse effect is greater risk of injury, which may be severe and long lasting. "Children and adolescents with developing bodies are at special risk of permanent physical damage if injury occurs to the growth plates of long bones or to other bone or connective tissue structures." (UDHHS 1996, p. 142) 
In spite of the limited scope for improvement, the Surgeon General's report on Physical Activity and Health (USDHHS 1996) and the report of The President's Council on Fitness and Sports (USDHHS 1997) identify some positive health benefits of youth physical activity. One of the most important potential benefits is improved blood lipid profiles and lower blood pressure, two risk factors associated with coronary heart disease. Further, several studies have shown a correlation between physical activity in children and lower risks of coronary heart disease. However, most of this evidence is from observational studies, and the significant association is eliminated when controls for weight are introduced, suggesting that most of the improvement in blood lipid profiles associated with physical activity is through weight control.

There is considerable clinical evidence that exercise and physical activity favorably affect body composition, weight and fat distribution. Intervention studies have demonstrated that physical activity and exercise can help control weight (Stefanick 1993; Slattery et al.1992). In addition, sports participation has been shown to increase vegetable consumption in high school students (Pate et al. 2000). However, observational studies of the relationship between physical activity and child obesity have reported inconsistent findings (USDHHS 1996; Kimm 2005). In sum, despite the potential for harm, there is evidence that adolescent health, specifically weight and body composition, can be improved through greater physical activity.

Title IX resulted in an expansion of school-based athletic opportunities for adolescent girls. In addition, Title IX is credited with causing an expansion of community-based athletic opportunities for girls. These increases in athletic opportunities make it more likely that girls will be physically active. In economic terms, Title IX has lowered the price of sports participation. Consequently, there should be an increase in adolescent girls' physical activity and an improvement in their body composition (lower proportion fat). Here we assess this hypothesis directly by examining the effect of increased girls' participation in high school sports caused by Title IX on girls' physical activity, weight, body mass and body composition.

\section{Research Design and Methods}

The statistical analyses used in this paper are based on multivariate regression models that relate girls' physical activity, weight, body mass and body composition to girls' participation in high school sports. Girls' high school sports participation is used as a proxy measure of changes in adolescent girls' athletic opportunities 
caused by Title IX. We obtain estimates of the regression model in the context of a research design intended to identify the "causal" effect of Title IX and the increase in girls' sports participation on adolescent health and health behaviors. Specifically, we rely on two approaches: a comparison group approach and instrumental variables. However, before describing these approaches, we discuss the assumption that Title IX is a good "natural experiment."

\section{Is Title IX a Good Natural Experiment?}

Earlier in the paper we provided evidence of the effect of Title IX on girls' sports participation and concluded that Title IX caused a significant increase in girls' sports participation. This is important because it established that part of the change in girls' sports participation was policy driven and unrelated to changes in personal characteristics and changes in social norms. In other words, part of the increase in girls' sports participation over the period we analyze is exogenous; Title IX provides a source of exogenous variation in athletic opportunities that can be used to help identify the causal effect of youth physical activity on adolescent female weight. Similarly, we provided evidence related to the effect of Title IX on boys' sports participation and concluded that it did not affect this outcome. This finding is important because one of the empirical strategies we employ is a comparison group approach that assumes that Title IX had no effect on boys. The descriptive information presented above supports this assumption and bolsters the credibility of the comparison group approach.

\section{Comparison Group Approach}

We obtain estimates of the effect of Title IX, as measured by changes in girls' high school sports participation, on physical activity, weight, body mass, and body composition using multivariate regression methods. The primary problem with this approach is to distinguish the effect girls' sports participation from the effect of unmeasured factors that vary over time, for example changes in women's attitudes about body image and physical activity. One way to address this problem is to use a comparison group-similar persons who are unaffected by Title IX. We use males as a comparison group for females because the enactment of Title IX had little effect on their participation in high school sports. 
To illustrate this approach, we begin with a simple model of adolescent female body mass index (BMI). The sample used to estimate the model consists of female adolescents ages 12 to 17 . The model is as follows: (1) $B M I_{i j t}=\alpha_{i}+\beta_{j}+\delta_{t}+\gamma_{1} S P_{j t}+\gamma_{2} Z_{j t}+\varepsilon_{i j t}$

$i=12, \ldots, 17$

$j=1, \ldots, 51$

$t=1971, \ldots, 1980$

Equation (1) assumes that the body mass index of adolescent women in year $\mathrm{t}$ and in state $\mathrm{j}$ is a function of the level of girls' high school sports participation (SP) in year $t$ and in state $\mathrm{j}$, and other factors $(\mathrm{Z})$ that affect the body mass index of women in year $\mathrm{t}$ and in state $\mathrm{j}$. We omit individual subscripts and individual-level variables such as race and family income to conserve on notation, but these variables will be included. Equation (1) also controls for age (i), state (j), and year (t) effects. Since sports participation and physical activity may have cumulative effects on body mass and health, we also use the three year average (years t, t-1, and t-2) of girls' sports participation.

The problem with equation (1) is that information about Z-factors specific to a state and year other than girls' sports participation—is not readily available. For example, girls' physical activity, eating and substance use (e.g., cigarettes) are influenced by attitudes and preferences that may vary by state and year and which are likely to influence sports participation and body mass index. Similarly, community level factors that affect body mass index may vary by state and year and may be correlated with girls' sports participation. Thus, estimates of equation (1) may be biased by the omission of some Z. In fact, we have only two Z - the proportion of females aged 20 to 24 enrolled in postsecondary education programs and state per-capita income.

One way to address the omitted variable problem is to use a comparison group. To implement this procedure, a model similar to that specified by equation (1) is estimated using a sample of boys:

(2) $B M I_{i j t}=\tilde{\alpha}_{i}+\widetilde{\beta}_{j}+\widetilde{\delta}_{t}+\tilde{\gamma}_{1} S P_{j t}+\tilde{\gamma}_{2} Z_{j t}+\widetilde{\varepsilon}_{i j t}$

To obtain an estimate of the effect of sports participation on girls' BMI, we subtract the estimate of the effect of girls' sports participation $\left(\tilde{\gamma}_{1}\right)$ obtained using the sample of boys from the estimate of the effect of girls' sports participation $\left(\gamma_{1}\right)$ obtained using the sample of girls. Note that in the boys' analysis, girls' sports participation would still be used as the measure of sports participation. The purpose of using boys as a comparison group is 
to investigate whether omitted variables that affect body mass index are correlated with girls' sports participation. So it is girls' sports participation that needs to be included in the boys' analysis. We expect $\tilde{\gamma}_{1}$ to be zero unless girls' sports participation is correlated with omitted variables that affect body mass index.

The identifying assumption of the comparison group approach is that the effects of unmeasured, statespecific, time-varying factors that affect BMI are the same for boys and girls. One way to assess the validity of this assumption is to investigate whether measured variables that differ by state and year have the same effect on boys and girls, and whether the effect of time dummy variables are the same. Specifically, we can pool the samples of boys and girls and estimate the following:

(3) $B M I_{i j t}=\tilde{\alpha}_{i}+\left(\alpha_{i}-\tilde{\alpha}_{i}\right) F E M+\widetilde{\beta}_{j}+\left(\beta_{j}-\widetilde{\beta}_{j}\right) F E M+\widetilde{\delta}_{t}+\left(\delta_{t}-\tilde{\delta}_{t}\right) F E M+\tilde{\gamma}_{1} S P_{j t}+\left(\gamma_{1}-\tilde{\gamma}_{1}\right) F E M * S P_{j t}$ $+\tilde{\gamma}_{2} Z+\left(\gamma_{2}-\tilde{\gamma}_{2}\right) F E M * Z_{j t}+\widetilde{\varepsilon}_{i j t}$

Using equation (3), we can test the following restrictions to provide evidence related to the identifying assumption of the comparison group approach:

(4) $\delta_{t}=\tilde{\delta}_{t}$

$\gamma_{2}=\tilde{\gamma}_{2}$

Rejecting the restrictions of equation (4), while not a definitive rejection of the comparison group approach, surely raises questions as to validity. In fact, we cannot reject the restrictions given in equation (4). ${ }^{2}$ This provides some important evidence to support the validity of the comparison group approach.

\section{Instrumental Variables}

The second research design we use is instrumental variables (IV). The IV procedure depends on the availability of a variable that is correlated with girls' sports participation, but not correlated with female adolescent body mass index (physical activity) after controlling for the effect of girls' sports participation and other observed determinants.

Stevenson (2000) uses an instrumental variables approach to estimate the effect of Title IX on female educational achievement and employment. The key insight of Stevenson is that the regulatory burden of Title

\footnotetext{
${ }^{2}$ The only restriction we rejected was $\gamma_{2}=\tilde{\gamma}_{2}$ when the dependent variable was physical activity. In all other cases we failed to reject the restriction in equation (4), although the imprecision of the estimates fails to reject some relatively large differences..
} 
IX differed by state, as boys' sports participation differed significantly by state prior to Title IX (National Federation of State High School Associations, 2001). If girls' interest in sports in a state is proportional to boys' interest in sports, then the change in female sports participation in response to Title IX is likely to be higher in states with high boys' participation than in states with low boys' participation. Therefore, we can use the level of boys' sports participation prior to implementation of Title IX as an indicator of the magnitude of the induced change brought about by Title IX. ${ }^{3}$

The IV approach is based on the following regression model, which again is estimated on individual level data consisting of females between the ages of 12 and 17:

(5) $B M I_{i j t}=\alpha_{i}+\beta_{j}+\delta_{t}+\gamma_{1} S P_{j t}+\gamma_{2} Z_{j t}+\varepsilon_{i j t}$

(6) $S P_{j t}=\pi_{i}+\phi_{j}+\lambda_{t}+\theta_{1}\left(Y R S_{t} * S P^{M}{ }_{j(1971)}\right)+u_{j t}$

In equation (6), the variable $\left(Y R S_{t}\right)$ is the number of years since Title IX was implemented, and the variable $\left(S P_{j(1971)}^{M}\right)$ is the boys' sports participation rate in state $\mathrm{j}$ in 1971.

There are two critical aspects of the IV procedure. The first is whether the instruments will be sufficiently correlated with girls' sports participation? The answer to this is a qualified yes. The t-statistic (fstatistic) associated with the coefficient on the instrument $\left(Y R S_{t} * S P_{j(1971)}^{M}\right)$ is 6.13 (37.6), which is a relatively strong partial correlation according to research assessing the adequacy of instruments (Bound, Jaeger and Baker 1995). ${ }^{4}$ However, as we show below, IV estimates of the effect of girls' sports participation are still too imprecise to be informative.

The second criterion is whether the instrument can be excluded from equation (5). Essentially this is a question of whether boys' participation in 1971 in state $\mathrm{j}$ is correlated with unmeasured factors that determine female adolescent body mass and which vary by year $(\mathrm{t})$ state $(\mathrm{j})$, holding constant state and year effects. Consider cigarette smoking. Changes in social norms and advertising by tobacco companies resulted in a significant increase in cigarette smoking among girls age 14 to 17 in the 1970s that may have affected weight and body composition. Are the state-specific changes in smoking during this period (e.g., 1972 to 1980) likely

\footnotetext{
${ }^{3}$ We also used the difference between boys' and girls' sports participation in 1971 as an instrument and obtained very similar results to those reported below.

${ }^{4}$ The reported test statistics were calculated using standard errors that allowed for non-independence (clustering) of observations within state-year.
} 
to be correlated with boys' sports participation in 1971? Was the increase in girls' cigarette smoking in North Dakota, Vermont, Minnesota, Oregon and Missouri, states with high boys' sports participation, different from the increase in girls' cigarette consumption in North Carolina, Rhode Island, Florida, Alabama and Utah, states with low boys' sports participation? We do not know the answer, but we see no obvious reason to think that there is a systematic correlation between boys' sports participation in 1971 and changes in girls' cigarette consumption, particularly holding constant state and year effects. While we believe the exclusion restriction is reasonable (valid), the relatively imprecise IV estimates we obtain make it a moot issue. Therefore, we do not discuss it further.

\section{Data}

The data for the empirical analyses comes primarily from the First and Second National Health and Nutritional Examination Surveys (NHANES I and II), which provide information on adolescent (age 12 to 17) physical activity and weight between the years 1971 and 1980, the period of most rapid growth in girls' participation in high school sports. We limit the sample to adolescents between the ages of 12 and 17 since data on physical activity is unavailable for younger children. The age restriction results in a sample of approximately 3,300 children. ${ }^{5}$

One important advantage of the NHANES is that it includes objective measures of anthropometric indicators such as height and weight. We use several different measures of weight and body composition:

- $\quad$ weight (conditional on height);

- $\quad$ body mass index = weight (kilograms) $/$ height2 (meters);

- $\quad$ indicators of $\mathrm{BMI} \geq 24, \mathrm{BMI} \geq 26$, and $\mathrm{BMI} \geq 28$;

- $\quad$ indicators of overweight (BMI $\geq 85$ percentile NHANES I) and obesity (BMI $\geq 95$ percentile NHANES I) based on BMI;

- $\quad$ triceps skinfold in right arm (in mm);

\footnotetext{
${ }^{5}$ The NHANES I and II have information on 4050 non-emancipated (not living alone) adolescents ages 12 to 17 at the time of interview. Missing data on girls' sports participation results in a loss of 774 observations.
} 
- indicators of overweight (triceps skinfold $\geq 85$ percentile NHANES I) and obesity (triceps skinfold $\geq 95$ percentile NHANES I) based on triceps skinfold;

- $\quad$ subscapula skinfold in chest (in $\mathrm{mm}$ );

- and the sum of triceps and subscapula skinfolds.

There is considerable debate over how best to measure body fat in adolescents, which is the key aspect of body composition that has been linked to greater morbidity and which is likely to be affected by greater physical activity (Goran 1998). Here we use a variety of commonly used measures that are available in the NHANES. However, we note that none of the measures we use is ideal because none precisely measure the proportion of body fat, which is the measure that is most likely to be altered by increased exercise and physical activity. For example, increased physical activity may actually increase body mass index.

The only non-standard measures we use are the indicators of BMI that are greater than a specific threshold (e.g., 28). One reason we use these is because the definitions of overweight and obese that depend on an adolescent's position in the BMI distribution (e.g., BMI $\geq 85$ percentile) are based on data from NHANES I. Since we are using observations from NHANES I, this may introduce a mechanical bias in these relative measures of overweight and obesity. Consider the following. Assume that greater athletic opportunities affected body mass of girls in the latter part (e.g., 1974) of the NHANES I study period. Thus, the definitions of overweight and obesity based on the NHANES I data will reflect the impact of Title IX. To avoid this we use the absolute cutoffs of BMI. The disadvantage of this approach is that boys and girls have different BMI distributions. So the proportion of the sample above a specified threshold will be different for boys and girls. For example, nine percent of girls in our sample (NHANES I and II) have a BMI greater than 26, but only seven percent of boys have a similar BMI. This may affect estimates obtained using the comparison group approach, since these estimates are based on the absolute difference between boys and girls. A one percentage point increase in the proportion of boys over the $\mathrm{BMI}=26$ threshold represents a 14 percent increase and indicates a greater degree of "obesity" than a similar increase in females, which represents a 11 percent increase.

Fortunately, the differences in the distributions of BMI between girls and boys are not that large, and as we show below, the inferences drawn from estimates obtained using the comparison group approach do not depend on small relative changes, but rather on fundamentally different associations between boys and girls BMI and 
girls' sports participation.

Recreational activity levels were obtained in NHANES I and II for persons ages 12 and over. The question related to recreational activity is not ideal and refers to the amount of exercise obtained from any (recreational) activity such as sports, hiking and dancing. Specifically, in NHANES I, the question was:

"Do you get much exercise in things you do for recreation?"

\section{And in NHANES II:}

"In things you do for recreation, e.g. sports, hiking, dancing and so forth, how much exercise do you get?"

For both surveys the responses were: 0 for little or no exercise, 1 for moderate exercise, and 2 for much exercise. We collapse the two lowest categories ( 0 and 1$)$ into one category $(0)$ to create a dichotomous indicator of engaging in much exercise. The change in the wording of the exercise question between the two NHANES surveys resulted in a significant decrease in the proportion of the sample that engaged in much exercise. However, the change was apparent for both boys and girls and should be adequately controlled for through the inclusion of year dummy variables.

The key demographic and socioeconomic variables in the NHANES surveys are age, race/ethnicity, gender, place of birth, years of school completed, family income, number of persons in the family, and number of children. For the head of the household, there is information about gender (of head), age, and years of formal schooling completed. We create gender-specific measures of the household head's age and schooling and we allow family income to have different effects depending on gender of household head.

Data on girls' high school sports participation comes from the National Federation of State High School Associations (NFSHSA), which maintains data on participation in competitive high school sports by year, state, sport and gender. The participation survey has been compiled every year since 1971 by the NFSHSA through cooperation with its member associations. No information is available for 1972, 1974 and 1976. For these years we use the average of the year prior and year following the missing information. There are also some obvious reporting errors in the data, as described above. While the data are crude, they serve the intended purpose, which is to proxy for the expanded athletic opportunities that occurred subsequent to Title IX. To calculate the girls' sports participation rate in each state and year, we divide the number of girls reported to have 
participated in high school sports by the population of girls ages 14 to 17 . The population data come from the 1970 and 1980 US Censuses. $^{6}$

We use two different measures of girls' sports participation: the contemporaneous participation rate and the three-year average (years t, t-1, and t-2). To calculate the average girls' sports participation in the early years of the period, when data on girls sports participation was not available, we use two methods: we assume either that girls' sports participation prior to 1971 was the same as it was in 1971, or that girls' sports participation prior to 1971 was zero. Given that girls' sports participation was quite low prior to 1971 (average rate of participation in 1971 was 4\%), the two methods produce almost identical results (see appendix). Because of confidentiality and disclosure rules, the NCHS does not provide state of current residence in the public use NHANES files. Therefore, we use state of birth instead of state of residence to merge on information about girls' sports participation. Given the ages of the sample, 12 to 17 , there is little difference between state of birth and state of residence. ${ }^{7}$

We also augment the NHANES data with data on state per-capita income and women's enrollment in postsecondary education in state $\mathrm{j}$ and year $\mathrm{t}$. Specifically, we construct a measure of female participation in postsecondary education by dividing the number of females enrolled (fall) in institutions of higher education by the number of females ages 20 to 24 . The data on postsecondary enrollment come from a survey by the National Center for Education Statistics entitled Higher Education General Information Survey, which is publicly available beginning in 1968. These data are reported by state of enrollment and year and include information on both private and public universities. Data on the population comes from 1970 and 1980 Censuses.

\footnotetext{
${ }^{6}$ Using 1\% public-use samples (PUS) of Census 1970 and 5\% public-use samples (PUMS) of Census 1980, we derive the number of boys and girls aged 14-17 for each state from 1971-1980. The basic idea of our procedure is that, for example, the number of boys and girls aged 15-18 in Census 1980 is a good proxy for the number of boys and girls aged 14-17 in each state in 1979. This ignores migration and death at young age. To correct the potential bias which may be induced by this assumption, we employ a similar procedure to obtain another proxy of same group of people, by calculating the number of boys and girls aged 5-8 in Census 1970. The more accurate estimate of the number of boys and girls aged 14-17 in each state is then equal to the weighted average of these two proxies, where the weight depends on the time difference between the year of each proxy and the year 1970. Using same reasoning process, we can also derive the number of boys and girls aged 14-17 for each state from 1971-1978. The above procedure is shown by the following equation:

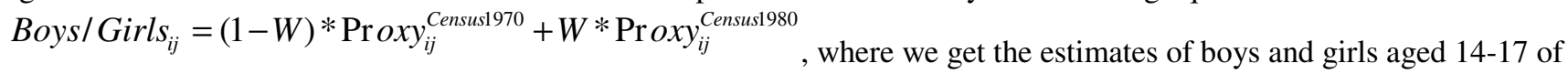
state $i$ in year $\mathrm{j}(\mathrm{j}=1971, \ldots 1979)$ and $\mathrm{W}=(\mathrm{j}-1970) / 10$.

${ }^{7}$ In private correspondence, a researcher with access to the confidential data reported that $85 \%$ of adolescents ages 12 to 17 in NHANES II lived in the same state they were born in.
} 


\section{Descriptive Analysis}

Table 1 provides the weighted, sample proportions and means for boys and girls from NHANES I (1971-1975) and NHANES II (1976-1980). The top half of Table 1 provides descriptive statistics for the dependent variables. The figures show that boys are significantly more physically active than girls, and boys have significantly lower BMI and skinfold measurements than girls. These facts are well-known (Must et al. 1991). The figures related to physical activity illustrate the effect of the questionnaire wording change between NHANES I and NHANES II. The proportion of boys and girls that engage in much physical exercise decreased markedly (11 to 13 percentage points) between NHANES I and NHANES II. However, there does not appear to be a relatively smaller decrease in physical activity among girls than boys, which would be expected given the expansion of athletic opportunities (i.e., girls high school sports participation) between the two periods. In contrast, there was relative improvement in girls' BMI, which remained basically unchanged between the two periods whereas the BMI of boys increased significantly. Similarly, there was a relative improvement in the probability of being overweight. But the probability of having a BMI greater than 26 or 28 increased for girls relative to boys, and similar relative increases for girls are observed for the absolute measures of Triceps and Subscapula skinfolds.

The bottom half of Table 1 provides the weighted, sample proportions and means for the control variables used in the analysis. NHANES I and II provide information on relatively few socioeconomic and demographic characteristics, and we have selected most of those available. The most important point to take away from these figures is that there are few differences between girls and boys, and the significant differences that are observed are relatively small and only marginally significant. Girls have more education than boys, but this difference is only significant in NHANES I, and girls come from households with a slightly higher number of members, but again, this difference is only significant in NHANES I. In NHANES II, girls are more likely to live in a female headed household than boys and in households headed by persons who are more educated. As noted, none of these differences are quantitatively large and all are only marginally significant.

In general, the simple descriptive evidence in Table 1 is not consistent with the hypothesis that Title IX expanded athletic opportunities resulting in greater physical activity and improved weight. However, what is 
ignored in Table 1 is that there are significant differences in the effect of Title IX, as it increased athletic opportunities much more in some states than others. We address this shortcoming by examining changes in sample means and proportions between NHANES I (1971-75) and NHANES II (1976-80) by whether a state experienced a relatively large increase in girls' sports participation. Specifically, we divide states into tertiles depending on the change in girls' sports participation between 1971-75 and 1976-80. ${ }^{8}$ Then we examine changes in physical activity, BMI and obesity between 1971-75 and 1976-80 for girls and boys. We construct simple difference-in-difference estimates using boys as a comparison group for girls. Results are presented in Table 2, which shows the results for states in the top and bottom tertiles.

Estimates in Table 2 provide some support for the hypothesis that Title IX and girls' sports participation increased physical activity and improved weight of adolescent girls. In states with relatively large increases in girls' sports participation (top tertile) between 1971-75 and 1976-80, girls' physical activity increased and boys' physical activity decreased. The difference-in-differences estimate for states in the top tertile indicates that girls' physical activity increased by 43 percentage points. The equivalent estimate for states in bottom tertile is 13 percentage points. Similarly, BMI and the probability of being obese decreased for girls in states that experienced a large increase in girls' sports participation whereas BMI and obesity remained relatively unchanged in states that experienced a relatively small increase in girls' sports participation. Difference-indifferences estimates suggest a significant 2-unit decline in BMI for girls in states that had relatively large increases in girls' sports participation. Among states in the bottom tertile, difference-in-differences estimates are small and not statistically significant. We now turn to the regression estimates, which refines the analysis in Table 2.

\section{Regression Results}

Our goal is to obtain estimates of the effect of girls' sports participation on the physical activity and weight of adolescent girls. The girls' sports participation rate is a proxy for expanded athletic opportunities caused by Title IX. To obtain estimates that can plausibly be interpreted as causal, we use two approaches: a

\footnotetext{
${ }^{8}$ Tertiles were derived using state-level data (not weighted). The top tertile consists of the following states: CO,CT,ID,KS,ME,MA,MI,MO,MT,NH,OK,OR,SD,TX,WA, and WY. The bottom tertile consists of the following states: AL,CA,FL,GA,IN,KY,LA,MN,MS,NV,NY,NC,ND,SC, UT and VA.
} 
comparison group approach in which boys are used as the counterfactual outcome, and instrumental variables. Table 3 provides these estimates. Estimates in Table 3 were obtained using a three-year average of girls' sports participation with years prior to 1971 set equal to 1971. Estimates using two different measures of girls' sports participation are provided in the appendix, and results from these alternative measures are very similar to those reported.

The first column of Table 3, labeled Female, presents estimates of equation (1) obtained using a sample of adolescent girls. These estimates basically measure the pre- and post-Title IX changes in physical activity, weight and body mass using girls' sports participation as a gauge the policy impact of Title IX. The estimate in the first row indicates that a 20 percentage point increase in girls' sports participation, which is roughly the increase associated with Title IX, is associated with a 10.6 percentage point (17\% of NHANES I mean) increase in the probability that an adolescent female will engage in recreation that includes "much" physical activity.

Estimates in the remaining rows of column (1) indicate that the increase in girls' sports participation associated with Title IX is associated with a decrease in BMI, weight, and measures of overweight and obesity. However, most estimates are not statistically significant even though some are quite large in magnitude. For example, a 20 percentage point increase in girls' sports participation is associated with a 2.4 percentage point (40\% of NHANES I mean) decrease in the probability of being obese. This is a relatively large effect, but the standard error of this estimate is also relatively large. Changes in girls' sports participation is significantly and negatively related to the probability of having a BMI greater than or equal to 26. Overall, estimates in column (1) suggest that the increase in girls' sports participation caused by Title IX was associated with an increase in physical activity and lower weight and BMI.

Estimates in column (2) of Table 2 were obtained using a sample of adolescent boys. The difference between these estimates and those for girls is striking. Among boys, increases in girls' sports participation are associated with a statistically significant decrease in physical activity and significant increases in weight, BMI, measures of overweight and obesity (based on BMI) and skinfold. During the period when girls' sports participation was increasing, and when girls were becoming more physically active with improved weight and body mass, boys were becoming less physically active and their weight and body mass were deteriorating. A 20 percentage point increase in girls' sports participation, the general impact of Title IX, is associated with a 1.02 
(five percent) increase in BMI, and an increase in the probability:

- of having a BMI greater than or equal to 24 of 9.6 (74\%) percentage points;

- of having a BMI greater than or equal to 26 of 5.2 (74\%) percentage points;

- of having a BMI greater than or equal to 28 of 3.8 (95\%) percentage points;

- and of having a probability of being obese $4.2(84 \%)$ percentage points;

Again, while estimates are large so are standard errors, which reflects the relatively small sample sizes and the fact that girls' sports participation does not vary by individuals, but rather by state and year and the calculation of standard errors that cluster on state.

The fact that girls' sports participation is significantly related to boys' weight and body mass merits some further discussion. These results indicate that there is an unobserved variable that is correlated with boys' weight and body mass that is also correlated with girls' sports participation. The underlying assumption of the research design implies that this unobserved variable has the same effect on girls. The troubling question is what this factor could be and why would it have a relatively large negative effect on girls' and boys' weight and body mass? Ideally, we would have observed no correlation between girls' sports participation and boys' weight and body mass. One potential answer is that boys were adversely affected by increases in girls' sports participation (athletic opportunities), as suggested by critics of Title IX legislation. If true, this possibility invalidates the comparison-group research design. While we have provided some evidence that the comparisongroup approach is valid, this evidence was not definitive. So we have to allow for this possibility, although we do not believe it the most likely explanation. Other explanations of this finding are less obvious, particularly because of the correlation of this unobserved factor with girls' sports participation. For example, consider two of the commonly cited explanations of rising obesity: an increasingly sedentary life and decreasing food prices (Cutler, Glaeser and Shapiro 2003). Changes in these factors during the 1970s may explain the increase in weight and body mass implied by the estimates in column (2), but why would changes in these factors be correlated with increases in girls' sports participation? While it is possible, we can bring no evidence to bear to establish its likelihood. However, we did provide evidence that the comparison-group approach is valid, specifically the finding that unobserved trends in weight and body mass are the same for boys and girls and that the effect of increasing school enrollment on weight and body mass is the same for boys and girls. These 
findings imply that the effect of other unobserved factors would be the same for boys and girls, specifically those factors that are correlated with girls' sports participation. However, the validity of this statement cannot be definitively established and is an assumption of the research design.

The third column of Table 3 presents difference-in-differences estimates, which were obtained using a sample of boys and girls. Note that estimates in column (3) are not equal to the exact difference between estimates in columns (1) and (2) because for all outcomes except physical activity, we restrict the year effects and the effect of female enrollment in higher education to be the same for boys and girls. In the case of physical activity, we allowed the effect of female enrollment in higher education to differ, but restricted year effects to be the same for boys and girls. All of these restrictions are supported by statistical tests. The validity of these restrictions is evidence that supports the assumptions of the comparison group approach.

Estimates in column (3) suggest that Title IX and the increase in girls' sports participation that it caused resulted in an increase in physical activity and an improvement in weight and body mass for adolescent females. A 20 percentage point increase in girls' physical activity is associated with a 14.6 percentage point (24\%) increase in the probability of engaging in "much" physical exercise during recreational activities. The same increase in girls' sports participation is associated with the following effects on weight and body mass:

- a 0.79 unit (3.8\%) decline in BMI;

- a 5.0 percentage point (28\%) decrease in the probability of being overweight;

- a 4.2 percentage point $(70 \%)$ decrease in the probability of being obese;

- and a 2.4 percentage point (48\%) decrease in the probability that Triceps skinfold is over 95 percentile;

The large confidence intervals of these estimates contain plausible results. For example, the 95 percent confidence interval for the difference-in-differences estimate of the effect of girls' sports participation on obesity is 0.05 to 0.37 ; so a 20 percentage point increase in girls' sports participation reduces obesity anywhere from one percentage point (17\%) to 7.4 percentage points (123\%). This is a large range and reflects the relative lack of precision of the estimate, but it also indicates that the confidence interval contains clearly plausible magnitudes of the estimate. Moreover, the uniformity of the estimates with respect to the various measures of weight and body mass provide strong evidence consistent with a true effect. 
The last column of Table 3 presents the instrumental variables (IV) estimates of the effect of girls' sports participation. ${ }^{9}$ No IV estimate is statistically significant and the magnitudes of the standard errors are very large. In general, the instrumental variables estimates are too imprecise to provide much information. While the first stage results suggest that the instrument, boys' sports participation in 1971 was significantly correlated with girls' sports participation (T-statistic of 6.1), this correlation was insufficient to produce precise estimates in the second stage given the sample size.

\section{Sensitivity Analyses}

To this point in the analysis, estimates indicate that girls' sports participation is associated with an increase in girls' physical activity and improvement in weight and body mass. To assess the robustness of these findings, we conducted three additional analyses. First, we examined the association between girls' sports participation and height. Girls' sports participation should not be associated with height, as there is no compelling biological mechanism to link changes in physical activity to changes in height. Estimates from this analysis are presented in the top row of Table 4. Girls' sports participation is associated with a statistically insignificant increase in height for both boys and girls. Estimates for both boys and girls are positive and the difference-in-differences estimate is virtually zero; a 20 percentage point increase in girls' sports participation was associated with a 0.11 inch (zero) increase in girls' height.

Second, we examined the effect of girls' high school sports participation on the weight, and body mass of children aged six to ten. While Title IX may have resulted in an expansion of athletic opportunities for female children, and there may have been a spillover within families from adolescents to children, the impact of Title IX should be much smaller among female children than among female adolescents. Estimates from this analysis are also presented in Table 4. Among female children, girls' participation in high school sports is associated with a decrease in weight, body mass and skinfold, but none of the estimates are statistically significant and standard errors are quite large. Among male children, we find similar results. Girls' high school sports participation is associated with a decrease in BMI, weight and probability of being obese and estimates related to obesity and weight are statistically significant. Standard errors are also quite large. The similar trends

\footnotetext{
${ }^{9}$ See Appendix Table 3 for a descriptive analysis of IV approach.
} 
in weight and body mass among male and female children yields difference-in-differences estimates that are generally smaller than the estimates for both boys and girls and estimates that are not statistically significant. The lone exception pertains to the probability of being overweight; girls' high school sports participation is associated with a large (70\%) decrease in a female child's probability of being overweight. However, the opposite is true for the probability of being obese - girls' high school sports participation is associated with an increase in a female child's probability of being obese.

Finally, we examined the effect of girls' high school sports participation on the height, weight, and body mass of adults ages 24 to 34 . Persons in this age group should be unaffected by Title IX because it was beyond high school age throughout the period of study. Estimates pertaining to the adult sample are with one exception not statistically significant. More importantly, there is no evidence that girls' sports participation in high school sports is associated with an increase in adult female physical activity or decrease in adult female weight and body mass. Further, difference-in-difference estimates do not indicate a relative improvement in these outcomes vis-à-vis adult males. In sum, estimates in Table 4 provide no evidence that the estimates in Table 3 are spurious.

\section{Conclusions}

In this study, we examined the association between girls' participation in high school sports and the physical activity and weight of adolescent females during the 1970s when girls' sports participation was dramatically increasing as a result of Title IX. We argued that girls' participation in high school sports is a good measure of athletic opportunities for adolescent girls, and that the dramatic rise in participation during the 1970s reflects an expansion of such opportunities for adolescent girls that effectively lowered the price of physical activity. As a result, we hypothesized that adolescent girls' physical activity would increase and in turn, result in an improvement in adolescent girls' weight and body mass.

Our statistical results bear this out. An increase in girls' participation in high school sports was associated with an increase in physical activity and an improvement in weight and body mass among adolescent girls. In contrast, boys experienced a decline in physical activity and an increase in weight and body mass during the period when girls' athletic opportunities were expanding. Taken together, these results strongly 
suggest that Title IX and the rapid increase in athletic opportunities it engendered had a beneficial effect on the health of adolescent girls. It resulted in greater physical activity and improved weight and body mass. The magnitudes of the effects were non trivial. The increase in girls' sports participation during the 1970s was approximately 20 percentage points. This change is associated with a $24 \%$ increase in physical activity, as measured by whether an adolescent engaged in "much" physical activity during recreation, and a four percent decline in BMI. The increase in girls' sports participation during the 1970s was associated with significantly larger improvements in the probability of being overweight and obese.

In sum, Title IX and the expansion of school-based opportunities for physical activity among adolescent girls that it caused appears to have had a significant causal effect on adolescent girls' physical activity and weight. These results provide evidence to support current calls for an expansion of school-based physical activities programs. Indeed, the magnitudes of the effects of expanded opportunity for physical activity among adolescent girls suggest that such programs will likely have a significant impact on obesity. These findings also illustrate the potential harm of the recent declines in school-based opportunity for exercise, for example, the percentage of high school students enrolled in daily physical education classes declined from 41.6 percent in 1991 to 28.4 percent in 2003 (Grunbaum et al., 2004).

A few limitations of the study should be acknowledged. First, we used girls' participation in high school sports to measure the impact of Title IX. Obviously, this is an indirect measure and as such may not accurately capture the impact of Title IX on adolescent girls' athletic opportunities. It would have been preferable to have more extensive measures of athletic opportunities including participation in community sports programs and intramural sports. This may partly explain some of the large estimates of the effect of girls' sports participation on some outcomes, as the scaling of the sports participation measure could affect the magnitude of the estimates. Moreover, data on girls' sports participation was noisy and was measured with a fair amount of error. At a minimum this will result in estimates biased toward zero. Similarly, information on physical activity is limited. If better measures were available, we could then directly measure physical activity and its relationship to body mass and health. Girls' sports participation and the "natural experiment" of Title IX could be used to overcome (i.e., instrument) the problem that girls physical activity may be correlated with unmeasured factors that affect both physical activity and obesity (health). In the absence of quality measures of 
physical activity, we were forced to use a more reduced form approach that relates girls' sports participation directly to the outcomes of interest. Finally, it would have been better if we had measures of weight that better reflect body composition and specifically the distribution of fat such as waist-to-hip ratio and measures of body composition determined by electrical impedance and X-ray absorptiometry.

Another limitation, particularly important to the instrumental variables approach, was that sample sizes were not sufficient to detect reliably small sized effects. The instrumental variables procedure relies on state level variables for identification and as a result requires relatively large samples to be effective. While NAHNES I and II provide reasonably large sample sizes, for example 3,300 adolescents, the power of the analysis was relatively low. Fortunately, many of the effects of interest were quite large and therefore we were able to reject the null hypothesis of no effect. 


\section{References}

American Friends Service Committee. 1977. "Almost as Fairly: The First Year of Title IX Implementation in Six Southern States." U.S. Department of Health, Education and Welfare; National Institute of Education, 2-143.

Boot A. M., de Ridder M. A. J., Pols H. A. P., Krenning E. P., de Muinck Keizer-Schrama. 1997. "Bone Mineral Density in Children and Adolescents: Relation to Puberty, Calcium Intake, and Physical Activity." The Journal of Clinical Endocrinology \& Metabolism, 82(1): 57-62.

Bound J., Jaeger D. A., Baker R. M. 1995. "On Potential Problems with Instrumental Variables Estimation When the Correlation Between the Instruments and the Endogenous Explanatory Variable is Weak." Journal of the American Statistical Association, 90: 443-450.

Cawley, J., Meyerhoefer, C., Newhouse D. 2005. "The Impact of State Physical Education Requirements on Youth Physical Activity and Overweight.” NBER Working Paper \#11411, Cambridge: NBER.

Centers for Disease Control and Prevention. 1997. "Guidelines for School and Community Programs to Promote Lifelong Physical Activity Among Young People." Morbidity and Mortality Weekly Report 46(RR-6): 1-36.

Craig W. L. 1977. “Implementing Title IX.” NASSP Bulletin, January 1977.

Cutler, D.M., Glaeser E. L., Shapiro J. M. 2003. “Why have Americans Become more Obese?” Journal of Economic Perspectives 17(3):93-118.

Gavora J. 2002. Tilting the Playing Field: Schools, Sports, Sex and Title IX. California, San Francisco: Encounter Books.

Goran MI. 1998. "Measurement issues related to studies of childhood obesity: assessment of body composition, body fat distribution, physical activity, and food intake." Pediatrics. 101 :505-518.

Grunbaum, Jo Anne et al. 2004. "Youth Risk Behavior Surveillance - United States, 2003." Morbidity and Mortality Weekly Report, 53(SS-2): 1-29.

Institute of Medicine. 2002. "Dietary Reference Intakes for Energy, Carbohydrate, Fiber, Fat, Fatty Acids, Cholesterol, Protein, and Amino Acids"' Washington, DC. National Academies Press.

Kimm, S. Y. S., Glynn, N. W., Obarzanek, E., Kriska, A. M., Daniels, S. R., Barton, B. A., Liu, K. 2005. "Relation between the changes in physical activity and body-mass index during adolescence: a multicentre longitudinal study." The Lancet 366: 301-307.

Lake J. K., Power C., Cole T. J. 1997. "Child to Adult Body Mass Index in 1958 British Birth Cohort: Associations with Parental Obesity." Archives of disease in childhood, 77:376-380.

Lloyd T., Chinchilli V. M., Johnson-Rollings N., Kieselhorst K., Eggli D. F., Marcus R. 2000. "Adult Female Hip Bone Density Reflects Teenage, Sports-Exercise Patterns but not Teenage Calcium Intake.” Pediatrics, 106: 40-44.

McTigue K. M., Garrett J. M., Popkin B. M. 2002. "The Nature History of the Development of Obesity in a Cohort of Young U.S. Adults between 1981 and 1998." Annals of Internal Medicine, 136: 857-64.

Morris F. L., Naughton G. A., Gibbs J. L., Carlson J. S., Wark J. D. 1997. "Prospective Ten-Month Exercise Intervention in Pre-Menarcheal Girls and Positive Effects on Bone and Lean Mass." Journal of Bone and Mineral Research, 12: 1453-1462.

Must, A., Dallal G. E., Dietz, W. H. 1991. "Reference Data for Obesity: 85th and 95th Percentiles of Body Mass Index and Triceps Skinfold Thickness." American Journal of Clinical Nutrition, 53:839-46. 
National Center for Health Statistics. 2005. "Prevalence of Overweight Among Children and Adolescents: United States, 1999-2002. www.cdc.nchs/products/pubs/hestats/overwght99.htm, last accessed June 15, 2005.

National Federation of State High School Associations. 2002. Participation Survey 2002, Indianapolis, IN: National Federation of State High School Associations.

Pate R. R., Trost S. G. Levin S., Dowda.M. 2000. "Sports Participation and Health-Related Behaviors Among US Youth." Archives of Pediatrics and Adolescent Medicine, 154: 904-911.

Pottker, J., Fishel A. 1976. "Separate and Unequal: Sex Discrimination in Interscholastic Sports.” Integrated Education, 14(2): 3-7.

Riley B. 1976 "The Effect of Title IX of the Education Amendments of 1972 on the Administration of Girls' Competitive Athletic Programs in Selected Public High Schools of Texas.” East Texas School Study Council Fall, 1976.

Rowland T. W. 1996. "Athleticism, Physical Activity and Health in the Early Years: a Question of Persistence." Encyclopaedia of Sports Medicine Vol. 6, Ch.10.

Ruiz J. C., Mandel C., Garabedian M. 1995. "Influence of Spontaneous Calcium Intake and Physical Exercise on the Vertebral and Femoral Bone Density of Children and Adolescents." Journal of Bone Mineral Resources 10(5): 675-682.

Serdula M. K., Ivery D., Coates R. J., Freedman D. S., Williamson D. F., Byers T. 1993. "Do Obese Children Become Obese Adults? A Review of the Literature." Preventive Medicine, 22(2): 167-77.

Slattery M. L., McDonald A., Bild D. E., et al. 1992. "Associations of body fat and its distribution with dietary intake, physical activity, alcohol, and smoking in blacks and whites ." American Journal of Clinical Nutrition 55: 943-9.

Specker B. L. 1996. "Evidence of Interaction Between Calcium Intake and Physical Activity on Changes in Bone Mineral Density.” Journal of Bone Mineral Resources, 11: 1539-1544.

Staffo D. F. 1980. "Efforts of Selected New York State High School to Provide Equal Opportunity in Interscholastic Athletics." Review of Sports and Leisure, 5: 93-106.

Stefanick M. L. 1993. "Exercise and Weight Control ." Exercise and Sport Sciences Review, 21: 363-396.

Stevenson B. 2000. "Evidence on the Effect of Sports Participation Examining the Impact of Title IX." Unpublished manuscript, Department of Economics Harvard University.

US Department of Education. 2000. "Title IX and Sex Discrimination." URL:http://www.ed.gov/offices/OCR/docs/tix dis.html, website accessed June 2, 2003.

US Department of Education. 1997. "Title IX: 25 years of Progress URL http://www.ed.gov/pubs/TitleIX/title.html, website accessed May 5, 2006.

US Department of Education. 1997. "Title IX: 25 years of Progress URL http://www.ed.gov/policy/rights/reg/ocr/edlite-34cfr106.html, website accessed May 5, 2006.

US Department of Health and Human services.1996. "Physical activity and health: A report of the Surgeon General.” Washington, DC: US Government Printing Office.

US Department of Health and Human services.1997. "Physical activity and sports in the lives of girls: A Report By The Presidents Council on Physical Fitness and Sport." Washington, DC: US Government Printing Office. 
US Department of Health and Human Services. 2000. "Healthy People 2010: National Health Promotion and Disease Objectives.” Washington D C: US Govt. Printing Office.

Whitaker, R. C., Pepe M. S., Wright J. A., Seidel K. D., Dietz W. H. 1998. "Early Adiposity Rebound and the Risk of Adult Obesity." Pediatrics, 101(3): e5. 
Table 1: Descriptive Statistics of Dependent and Independent Variables, by Gender and Year

\begin{tabular}{|c|c|c|c|c|c|c|}
\hline \multirow[b]{2}{*}{ Variables } & \multicolumn{3}{|c|}{ 1971-1975 } & \multicolumn{3}{|c|}{ 1976-1980 } \\
\hline & $\begin{array}{c}\text { Boys } \\
(\mathrm{n}=720) \\
\text { Mean }\end{array}$ & $\begin{array}{c}\text { Girls } \\
(\mathrm{n}=733) \\
\text { Mean }\end{array}$ & $p$ value $^{3}$ & $\begin{array}{c}\text { Boys } \\
(\mathrm{n}=955) \\
\text { Mean }\end{array}$ & $\begin{array}{c}\text { Girls } \\
(\mathrm{n}=867) \\
\text { Mean }\end{array}$ & $p$ value $^{3}$ \\
\hline Physical Activity $^{1}$ & 0.80 & 0.62 & $<.0001 *$ & 0.69 & 0.48 & $<.0001 *$ \\
\hline BMI & 20.28 & 20.96 & $0.0006^{*}$ & 20.62 & 20.99 & $0.0386^{*}$ \\
\hline BMI $>=24$ & 0.13 & 0.17 & $0.0107 *$ & 0.13 & 0.15 & 0.3138 \\
\hline BMI $>=26$ & 0.07 & 0.09 & $0.0634 * *$ & 0.06 & 0.10 & $0.0137 *$ \\
\hline BMI $>=28$ & 0.04 & 0.05 & 0.1799 & 0.03 & 0.06 & $0.0150 *$ \\
\hline Overweight $(\mathrm{BMI}>=85$ percentile in NHANES I) & 0.14 & 0.18 & $0.0336^{*}$ & 0.16 & 0.15 & 0.7464 \\
\hline Obese $(B M I>=95$ percentile in NHANES I) & 0.05 & 0.06 & 0.5418 & 0.04 & 0.06 & $0.0617 * *$ \\
\hline Weight (pounds) & 125.79 & 119.73 & $<.0001^{*}$ & 128.26 & 120.46 & $<.0001$ \\
\hline Height (inches) & 65.63 & 63.25 & $<.0001^{*}$ & 65.74 & 63.41 & $<.0001 *$ \\
\hline Triceps Skinfold (TS) & 10.31 & 17.15 & $<.0001^{*}$ & 10.62 & 17.77 & $<.0001$ \\
\hline TS >= 85 percentile (in NHANES I) & 0.14 & 0.15 & 0.6221 & 0.13 & 0.17 & $0.0211 *$ \\
\hline TS >= 95 percentile (in NHANES I) & 0.07 & 0.05 & 0.1291 & 0.05 & 0.06 & 0.5628 \\
\hline Subscapular Skinfold (SS) & 8.85 & 12.52 & $<.0001^{*}$ & 9.76 & 13.76 & $<.0001 *$ \\
\hline Sum of TS and SS & 19.16 & 29.67 & $<.0001 *$ & 20.37 & 31.53 & $<.0001 *$ \\
\hline Girls' Contemporaneous Sports Participation Rate & 0.09 & 0.09 & 0.8708 & 0.23 & 0.22 & 0.3971 \\
\hline Female College Enrollment Percentage & 0.44 & 0.44 & 0.3160 & 0.53 & 0.53 & 0.7462 \\
\hline State Per-Capita Income in Real Term (1000 Dollars) & 11.00 & 11.03 & 0.7014 & 12.27 & 12.25 & 0.7449 \\
\hline White & 0.84 & 0.84 & 0.6691 & 0.84 & 0.84 & 0.9111 \\
\hline African American & 0.16 & 0.15 & 0.7711 & 0.15 & 0.15 & 0.6673 \\
\hline Other Race & 0.01 & 0.00 & 0.4241 & 0.01 & 0.01 & 0.2447 \\
\hline Age of Respondents & 14.49 & 14.49 & 0.9924 & 14.64 & 14.64 & 0.9272 \\
\hline Education of Respondents & 8.64 & 8.83 & $0.0489 *$ & 8.96 & 9.02 & 0.5073 \\
\hline Child of the Household Head ${ }^{2}$ & 0.95 & 0.96 & 0.4178 & 0.95 & 0.96 & 0.3345 \\
\hline Gender of Household Head (Male) & 0.83 & 0.85 & 0.2766 & 0.82 & 0.78 & $0.0514 * *$ \\
\hline Age of Household Head & 44.13 & 44.13 & 0.9999 & 43.92 & 43.59 & 0.3775 \\
\hline Education of Household Head & 11.08 & 10.96 & 0.5266 & 11.48 & 11.73 & $0.0946 * *$ \\
\hline Total Number of Person in Household & 5.47 & 5.68 & $0.0563 * *$ & 5.15 & 5.07 & 0.3677 \\
\hline Total Family Income & 18.04 & 18.11 & 0.6200 & 19.36 & 19.23 & 0.2234 \\
\hline Residence of SMSA & 0.61 & 0.62 & 0.8582 & 0.61 & 0.61 & 0.9469 \\
\hline
\end{tabular}

Notes: Descriptive statistics are calculated using sample weights from NHANES I \& II. 1. Physical activity is dichotomous variable: 1 for much exercise, and 0 for little, no or moderate exercise; 2 . child of the household head is a dichotomous variable, 1 for child of the household head, 0 for other relatives; 3 . P-value for t-test of means assumes equal variance. $* p \leq 0.05 ; * * p \leq 0.10$. 
Table 2. Descriptive Statistics of Dependent Variables by Change in Girls' High School Sports Participation Rate between 1971-1980

\begin{tabular}{|c|c|c|c|}
\hline \multirow{2}{*}{ Physical Activity } & \multicolumn{3}{|c|}{ Top Third States } \\
\hline & 1971-1975 & $1976-1980$ & Difference \\
\hline Girls & 0.610 & 0.887 & $\begin{array}{l}0.277 * \\
(0.116)\end{array}$ \\
\hline Boys & 0.829 & 0.679 & $\begin{array}{c}-0.150^{*} \\
(0.045)\end{array}$ \\
\hline \multirow[t]{2}{*}{ Diff-in-Diff } & & & $\begin{array}{l}0.427^{*} \\
(0.148)\end{array}$ \\
\hline & \multicolumn{3}{|c|}{ Bottom Third States } \\
\hline Girls & 0.674 & 0.692 & $\begin{array}{c}0.018 \\
(0.104)\end{array}$ \\
\hline Boys & 0.790 & 0.681 & $\begin{array}{c}-0.109^{*} \\
(0.041)\end{array}$ \\
\hline Diff-in-Diff & & & $\begin{array}{c}0.127 \\
(0.131)\end{array}$ \\
\hline BMI & \multicolumn{3}{|c|}{ Top Third States } \\
\hline Girls & 21.296 & 19.554 & $\begin{array}{c}-1.742 * * \\
(0.937)\end{array}$ \\
\hline Boys & 20.212 & 20.482 & $\begin{array}{c}0.270 \\
(0.364)\end{array}$ \\
\hline \multirow[t]{2}{*}{ Diff-in-Diff } & & & $\begin{array}{c}-2.012 * * \\
(1.205)\end{array}$ \\
\hline & \multicolumn{3}{|c|}{ Bottom Third States } \\
\hline Girls & 20.366 & 20.362 & $\begin{array}{l}-0.004 \\
(0.996)\end{array}$ \\
\hline Boys & 20.223 & 20.783 & $\begin{array}{l}0.560^{*} \\
(0.304)\end{array}$ \\
\hline Diff-in-Diff & & & $\begin{array}{r}-0.564 \\
(0.953) \\
\end{array}$ \\
\hline Obese & 1971-1975 & $\begin{array}{l}\text { p Third Sta } \\
1976-1980\end{array}$ & Difference \\
\hline Girls & 0.070 & 0.018 & $\begin{array}{l}-0.052 \\
(0.052)\end{array}$ \\
\hline Boys & 0.041 & 0.042 & $\begin{array}{c}0.001 \\
(0.957)\end{array}$ \\
\hline \multirow[t]{2}{*}{ Diff-in-Diff } & & & $\begin{array}{c}-0.053 \\
(0.067)\end{array}$ \\
\hline & \multicolumn{3}{|c|}{ Bottom Third States } \\
\hline Girls & 0.039 & 0.062 & $\begin{array}{c}0.023 \\
(0.036)\end{array}$ \\
\hline Boys & 0.040 & 0.044 & $\begin{array}{c}0.004 \\
(0.020)\end{array}$ \\
\hline Diff-in-Diff & & & $\begin{array}{c}0.019 \\
(0.051)\end{array}$ \\
\hline
\end{tabular}

Note: Standard errors in parentheses. $* p \leq 0.05 ; * * p \leq 0.10$ 
Table 3

Difference-in-Difference Estimates of the Effect of Girls' Sports Participation on Physical Activity and Weight (3-Year Average Sports Participation Rate, Participation Rate prior to 1971 = Participation Rate in 1971)

\begin{tabular}{|c|c|c|c|c|}
\hline \multirow[b]{2}{*}{ Variables } & \multicolumn{4}{|c|}{ High School Sport Participation Rate } \\
\hline & Female & Male & DD & IV \\
\hline \multirow{2}{*}{ Physical Activity } & $0.53^{*}$ & $-0.47 *$ & $0.73 *$ & 0.53 \\
\hline & $(0.23)$ & $(0.19)$ & $(0.25)$ & $(0.40)$ \\
\hline \multirow[t]{2}{*}{ BMI } & -1.50 & $5.14^{*}$ & $-3.96^{*}$ & -0.66 \\
\hline & $(1.65)$ & $(1.67)$ & $(1.48)$ & $(3.14)$ \\
\hline \multirow[t]{2}{*}{$\mathrm{BMI} \geq \mathbf{2 4}$} & 0.03 & $0.48 *$ & $-0.37 *$ & 0.11 \\
\hline & $(0.16)$ & $(0.15)$ & $(0.13)$ & $(0.32)$ \\
\hline \multirow[t]{2}{*}{$\mathrm{BMI} \geq 26$} & $-0.29 *$ & $0.26^{*}$ & $-0.26^{*}$ & -0.17 \\
\hline & $(0.14)$ & $(0.12)$ & $(0.11)$ & $(0.25)$ \\
\hline \multirow[t]{2}{*}{$\mathrm{BMI} \geq 28$} & -0.05 & $0.19 *$ & $-0.18 *$ & 0.04 \\
\hline & $(0.11)$ & $(0.09)$ & $(0.08)$ & $(0.20)$ \\
\hline \multirow[t]{2}{*}{ Overweight } & -0.02 & 0.27 & $-0.25 * *$ & 0.02 \\
\hline & $(0.17)$ & $(0.20)$ & $(0.14)$ & $(0.31)$ \\
\hline \multirow[t]{2}{*}{ Obese } & -0.12 & $0.21 * *$ & $-0.21 *$ & -0.04 \\
\hline & $(0.13)$ & $(0.12)$ & $(0.08)$ & $(0.19)$ \\
\hline \multirow[t]{2}{*}{ Weight } & -5.03 & $35.26^{*}$ & $-21.83^{*}$ & -2.30 \\
\hline & $(9.53)$ & $(10.21)$ & $(8.18)$ & (17.19) \\
\hline \multirow[t]{2}{*}{ Triceps Skinfold (TS) } & 1.88 & $7.55^{*}$ & $-4.17 * *$ & 1.90 \\
\hline & $(3.27)$ & $(3.35)$ & $(2.50)$ & $(6.16)$ \\
\hline \multirow[t]{2}{*}{$\mathrm{TS} \geq \mathbf{8 5 \%}$} & -0.07 & $0.39 *$ & -0.01 & -0.39 \\
\hline & $(0.17)$ & $(0.17)$ & $(0.13)$ & $(0.30)$ \\
\hline \multirow[t]{2}{*}{$\mathrm{TS} \geq 95 \%$} & -0.02 & 0.15 & $-0.12 * *$ & -0.09 \\
\hline & $(0.10)$ & $(0.10)$ & $(0.06)$ & $(0.16)$ \\
\hline \multirow{2}{*}{ Subscapular Skinfold (SS) } & -1.68 & 5.48 & -3.46 & 3.47 \\
\hline & $(3.54)$ & $(3.52)$ & $(2.62)$ & $(5.87)$ \\
\hline \multirow[t]{2}{*}{$\mathrm{TSS}=\mathrm{TS}+\mathrm{SS}$} & 0.20 & $13.04 * *$ & -7.63 & 5.37 \\
\hline & $(6.38)$ & $(6.70)$ & $(4.93)$ & (11.14) \\
\hline
\end{tabular}

Notes: Robust standard errors, clustered at state specific year level in parentheses. Regressions include controls for respondent demographic variables, such as indicators for gender, races, age in months, the difference between age and education level, and whether he/she is the child of the household head; family background variables, such as age, gender, years of education of household head, total family income, and number of person living in the household. Other control variables include indicators of metropolitan areas, sampling weight, proportion of female enrollment in postsecondary education programs and state per-capita income, state and year fixed effects, and interaction terms of family background variables with gender of household head. Weight regression contains additional controls of height in inches. The sample size of DD is 3050/3035(physical Activity), among them 1497/1489 are females and 1553/1546 are males. The sample size of IV estimation is $1497 / 1489 . * p \leq 0.05 ; * * \leq 0.10$. 
Table 4

Sensitivity Analyses

Difference-in-Difference Estimates of the Effect of Girls' Sports Participation on Physical Activity and Weight (3-Year Average Sports Participation Rate Participation Rate prior to 1971 = Participation Rate in 1971)

\begin{tabular}{|c|c|c|c|}
\hline \multirow[b]{2}{*}{ Variables } & \multicolumn{3}{|c|}{ 3-Year Average High School Sport Participation (HSSP) } \\
\hline & Female & Male & DD \\
\hline \multicolumn{4}{|l|}{ Adolescents (12-17) } \\
\hline Height & $\begin{array}{c}0.74 \\
(1.05)\end{array}$ & $\begin{array}{c}1.71 \\
(1.26)\end{array}$ & $\begin{array}{c}0.59 \\
(0.76)\end{array}$ \\
\hline \multicolumn{4}{|l|}{ Children (6-10) } \\
\hline BMI & $\begin{array}{l}-2.47 \\
(1.73)\end{array}$ & $\begin{array}{l}-1.85 \\
(1.22)\end{array}$ & $\begin{array}{l}-1.07 \\
(1.84)\end{array}$ \\
\hline Overweight & $\begin{array}{l}-0.44 \\
(0.28)\end{array}$ & $\begin{array}{c}0.01 \\
(0.18)\end{array}$ & $\begin{array}{c}-0.50 * * \\
(0.28)\end{array}$ \\
\hline Obese & $\begin{array}{l}-0.07 \\
(0.15)\end{array}$ & $\begin{array}{c}-0.22 * * \\
(0.12)\end{array}$ & $\begin{array}{c}0.12 \\
(0.17)\end{array}$ \\
\hline Weight & $\begin{array}{l}-9.66 \\
(6.61)\end{array}$ & $\begin{array}{c}-7.52 * * \\
(4.30)\end{array}$ & $\begin{array}{l}-4.62 \\
(7.25)\end{array}$ \\
\hline Triceps Skinfold (TS) & $\begin{array}{l}-0.43 \\
(3.99)\end{array}$ & $\begin{array}{c}1.33 \\
(2.47)\end{array}$ & $\begin{array}{l}-1.44 \\
(3.64)\end{array}$ \\
\hline Subscapular Skinfold (SS) & $\begin{array}{l}-1.70 \\
(3.48)\end{array}$ & $\begin{array}{l}-1.40 \\
(2.05)\end{array}$ & $\begin{array}{l}-2.32 \\
(3.17)\end{array}$ \\
\hline Adults (24-34) & & & \\
\hline Physical Activity & $\begin{array}{l}-0.27 * \\
(0.14)\end{array}$ & $\begin{array}{l}-0.36 \\
(0.27)\end{array}$ & $\begin{array}{c}0.12 \\
(0.29)\end{array}$ \\
\hline BMI & $\begin{array}{l}1.41 \\
(2.72)\end{array}$ & $\begin{array}{l}-0.08 \\
(2.63)\end{array}$ & $\begin{array}{c}1.08 \\
(4.52)\end{array}$ \\
\hline Overweight & $\begin{array}{c}0.31 \\
(0.22)\end{array}$ & $\begin{array}{c}0.10 \\
(0.28)\end{array}$ & $\begin{array}{c}0.22 \\
(0.39)\end{array}$ \\
\hline Obese & $\begin{array}{c}0.01 \\
(0.13)\end{array}$ & $\begin{array}{c}0.22 \\
(0.19)\end{array}$ & $\begin{array}{l}-0.26 \\
(0.26)\end{array}$ \\
\hline Weight & $\begin{array}{c}12.35 \\
(15.70)\end{array}$ & $\begin{array}{c}2.26 \\
(18.54)\end{array}$ & $\begin{array}{c}11.75 \\
(27.73)\end{array}$ \\
\hline Triceps Skinfold (TS) & $\begin{array}{c}6.71 \\
(4.21)\end{array}$ & $\begin{array}{c}1.52 \\
(5.13)\end{array}$ & $\begin{array}{c}3.95 \\
(6.97)\end{array}$ \\
\hline Subscapular Skinfold (SS) & $\begin{array}{c}1.08 \\
(4.81)\end{array}$ & $\begin{array}{c}3.86 \\
(5.85)\end{array}$ & $\begin{array}{l}-3.98 \\
(8.54)\end{array}$ \\
\hline
\end{tabular}

Notes: Robust standard errors, clustered at state specific year level in parentheses. (1) Regressions of Children include controls for individual demographic variables, such as indicators for gender, races, age in months, the difference between age and education level, and whether he/she is the child of the household head; family background variables, such as age, gender, years of education of household head, total family income, and number of person living in the household. Other control variables include indicators of metropolitan areas, real state per capita income, percentage of female postsecondary education enrollment, sampling weight, state and year fixed effects, and interaction terms of family background variables with gender of household head. Weight regression contains additional controls of height in inches. The sample size of children in DD estimation is 2353, among them 1162 are females and 1191 are males. (2) Regressions of Adults include controls for respondent demographic variables, such as indicators for gender, race, age, living quarters, education levels and marital status; family background variables, such as total family income, and number of person living in the household. Other control variables include indicators of metropolitan areas, real state per capita income, percentage of female postsecondary education enrollment, sampling weight, state and year fixed effects, and interaction terms of family background variables with gender of household head. Weight regression contains additional controls of height in inches. The sample size of adults in DD is 3606/3609 (physical activity), among them 2255/2252 (physical activity) are females and 1354 are males. $* p \leq 0.05 ; * * \leq 0.10$. 
Appendix Table 1

Difference-in-Difference Estimates of the Effect of Girls' Sports Participation

(3-Year Average Sports Participation Rate, Participation Rate prior to $1971=0$ )

\begin{tabular}{lcccc}
\hline & \multicolumn{3}{c}{ High School Sport Participation Rate } \\
\multicolumn{1}{c}{ Variables } & Female & Male & DD & IV \\
\hline Physical Activity & $0.55^{*}$ & $-0.43^{*}$ & $0.70^{*}$ & 0.53 \\
& $(0.21)$ & $(0.17)$ & $(0.23)$ & $(0.36)$ \\
BMI & -1.17 & $5.67^{*}$ & $-3.59^{*}$ & -0.34 \\
& $(1.55)$ & $(1.49)$ & $(1.32)$ & $(2.89)$ \\
BMI $\geq \mathbf{2 4}$ & 0.04 & $0.52^{*}$ & $-0.35^{*}$ & 0.16 \\
& $(0.15)$ & $(0.13)$ & $(0.12)$ & $(0.29)$ \\
BMI $\geq \mathbf{2 6}$ & $-0.22^{* *}$ & $0.24^{*}$ & $-0.21^{*}$ & -0.11 \\
& $(0.13)$ & $(0.11)$ & $(0.10)$ & $(0.23)$ \\
BMI $\geq \mathbf{2 8}$ & 0.03 & $0.20^{*}$ & $-0.14^{* *}$ & 0.07 \\
& $(0.10)$ & $(0.08)$ & $(0.07)$ & $(0.18)$ \\
Overweight & -0.01 & $0.36^{*}$ & $-0.25^{*}$ & 0.07 \\
& $(0.15)$ & $(0.18)$ & $(0.12)$ & $(0.29)$ \\
Obese & -0.04 & $0.21^{* *}$ & $-0.17^{*}$ & -0.00 \\
Weight & $(0.11)$ & $(0.11)$ & $(0.07)$ & $(0.17)$ \\
Triceps Skinfold (TS) & -3.33 & $38.30^{*}$ & $-19.82^{*}$ & -0.22 \\
TS $\geq \mathbf{8 5 \%}$ & $(8.94)$ & $(9.21)$ & $(7.32)$ & $(15.82)$ \\
& 2.29 & $8.13^{*}$ & -3.65 & 2.52 \\
TS $\geq \mathbf{9 5 \%}$ & $(3.06)$ & $(2.97)$ & $(2.22)$ & $(5.67)$ \\
Subscapular Skinfold (SS) & -0.09 & $0.42^{*}$ & -0.02 & -0.36 \\
TSS=TS+SS & $(0.16)$ & $(0.16)$ & $(0.12)$ & $(0.28)$ \\
& 0.04 & 0.15 & $-0.10^{* *}$ & -0.04 \\
& $(0.09)$ & $(0.09)$ & $(0.06)$ & $(0.15)$ \\
& -0.82 & 6.44 & -3.07 & 3.89 \\
& $(3.17)$ & $(3.18)$ & $(2.34)$ & $(5.39)$ \\
& 1.47 & $14.57^{*}$ & -6.73 & 6.41 \\
& $(5.84)$ & $(6.00)$ & $(4.39)$ & $(10.27)$ \\
\hline
\end{tabular}

Notes: See notes to Table 3. 
Appendix Table 2

Difference-in-Difference Estimates of the Effect of Girls' Sports Participation on Physical Activity and Weight Contemporaneous Sports Participation Rate

\begin{tabular}{|c|c|c|c|c|}
\hline \multirow[b]{2}{*}{ Variables } & \multicolumn{4}{|c|}{ High School Sport Participation Rate } \\
\hline & Female & Male & DD & IV \\
\hline \multirow[t]{2}{*}{ Physical Activity } & $0.61 *$ & -0.22 & $0.64 *$ & 0.63 \\
\hline & $(0.19)$ & $(0.19)$ & $(0.25)$ & $(0.39)$ \\
\hline \multirow[t]{2}{*}{ BMI } & -2.31 & $3.71 *$ & $-3.67 *$ & -1.07 \\
\hline & $(1.53)$ & $(1.65)$ & $(1.45)$ & $(3.35)$ \\
\hline \multirow[t]{2}{*}{$\mathrm{BMI} \geq \mathbf{2 4}$} & -0.11 & $0.30 * *$ & $-0.35 *$ & 0.10 \\
\hline & $(0.15)$ & $(0.17)$ & $(0.12)$ & $(0.36)$ \\
\hline \multirow[t]{2}{*}{$\mathrm{BMI} \geq \mathbf{2 6}$} & $-0.26 * *$ & $0.19 * *$ & $-0.20 * *$ & -0.17 \\
\hline & $(0.14)$ & $(0.11)$ & $(0.11)$ & $(0.26)$ \\
\hline \multirow[t]{2}{*}{ BMI $\geq 28$} & -0.02 & 0.13 & -0.10 & -0.03 \\
\hline & $(0.10)$ & $(0.09)$ & $(0.08)$ & $(0.21)$ \\
\hline \multirow[t]{2}{*}{ Overweight } & -0.19 & 0.15 & $-0.27 *$ & 0.01 \\
\hline & $(0.17)$ & $(0.19)$ & $(0.11)$ & $(0.35)$ \\
\hline \multirow[t]{2}{*}{ Obese } & -0.03 & 0.17 & -0.11 & -0.03 \\
\hline & $(0.10)$ & $(0.11)$ & $(0.09)$ & $(0.19)$ \\
\hline \multirow[t]{2}{*}{ Weight } & -10.17 & $22.63 *$ & $-18.84 *$ & -7.55 \\
\hline & $(9.04)$ & $(10.35)$ & $(8.12)$ & (18.68) \\
\hline \multirow[t]{2}{*}{ Triceps Skinfold (TS) } & -1.48 & 5.09 & -2.62 & 1.37 \\
\hline & $(3.40)$ & (3.34) & $(2.48)$ & $(6.70)$ \\
\hline \multirow[t]{2}{*}{$\mathrm{TS} \geq 85 \%$} & -0.17 & 0.26 & 0.02 & -0.30 \\
\hline & $(0.17)$ & $(0.18)$ & $(0.12)$ & $(0.33)$ \\
\hline \multirow[t]{2}{*}{$\mathrm{TS} \geq 95 \%$} & -0.03 & 0.05 & -0.06 & -0.00 \\
\hline & $(0.10)$ & $(0.09)$ & $(0.06)$ & $(0.17)$ \\
\hline \multirow[t]{2}{*}{ Subscapular Skinfold (SS) } & -4.00 & 3.31 & -2.76 & 1.21 \\
\hline & (3.34) & (3.39) & $(2.48)$ & $(6.36)$ \\
\hline \multirow[t]{2}{*}{$\mathrm{TSS}=\mathrm{TS}+\mathrm{SS}$} & -5.48 & 8.40 & -5.38 & 2.57 \\
\hline & $(6.49)$ & $(6.57)$ & $(4.79)$ & $(12.26)$ \\
\hline
\end{tabular}

Notes: See notes to Table 3. 
Appendix Table 3

Weighted Descriptive Statistics of Dependent Variables by Boys' Sports Participation Rate in 1971

\begin{tabular}{|c|c|c|c|}
\hline \multirow{2}{*}{ Physical Activity } & \multicolumn{3}{|c|}{ Top Third States } \\
\hline & 1971-1975 & $1976-1980$ & Diff \\
\hline Girls & 0.661 & 0.518 & $\begin{array}{l}-0.143 * \\
(0.061)\end{array}$ \\
\hline Boys & 0.765 & 0.646 & $\begin{array}{l}-0.119 * \\
(0.056)\end{array}$ \\
\hline \multirow[t]{2}{*}{ Diff-in-Diff } & & & $\begin{array}{l}-0.024 \\
(0.083)\end{array}$ \\
\hline & \multicolumn{3}{|c|}{ Bottom Third States } \\
\hline Girls & 0.663 & 0.463 & $\begin{array}{l}-0.200^{*} \\
(0.048)\end{array}$ \\
\hline Boys & 0.792 & 0.693 & $\begin{array}{l}-0.099 * \\
(0.043)\end{array}$ \\
\hline Diff-in-Diff & & & $\begin{array}{l}-0.101 \\
(0.064)\end{array}$ \\
\hline BMI & 1971-1975 & Top Third States & Diff \\
\hline Girls & 21.307 & 20.650 & $\begin{array}{l}-0.657 \\
(0.477)\end{array}$ \\
\hline Boys & 20.361 & 20.467 & $\begin{array}{c}0.106 \\
(0.405)\end{array}$ \\
\hline \multirow[t]{2}{*}{ Diff-in-Diff } & & & $\begin{array}{c}-0.763 \\
(0.626)\end{array}$ \\
\hline & \multicolumn{3}{|c|}{ Bottom Third States } \\
\hline Girls & 20.456 & 21.006 & $\begin{array}{c}0.550 \\
(0.366)\end{array}$ \\
\hline Boys & 20.553 & 20.682 & $\begin{array}{l}0.129 \\
(309)\end{array}$ \\
\hline Diff-in-Diff & & & $\begin{array}{c}0.421 \\
(0.479) \\
\end{array}$ \\
\hline Obese & 1971-1975 & $\begin{array}{l}\text { p Third Sta } \\
1976-1980\end{array}$ & Diff \\
\hline Girls & 0.077 & 0.046 & $\begin{array}{l}-0.031 \\
(0.031)\end{array}$ \\
\hline Boys & 0.038 & 0.007 & $\begin{array}{l}-0.031 \\
(0.020)\end{array}$ \\
\hline \multirow[t]{2}{*}{ Diff-in-Diff } & & & $\begin{array}{l}-0.000 \\
(0.037)\end{array}$ \\
\hline & \multicolumn{3}{|c|}{ Bottom Third States } \\
\hline Girls & 0.038 & 0.063 & $\begin{array}{c}0.025 \\
(0.018)\end{array}$ \\
\hline Boys & 0.044 & 0.051 & $\begin{array}{c}0.007 \\
(0.019)\end{array}$ \\
\hline Diff-in-Diff & & & $\begin{array}{c}0.018 \\
(0.026)\end{array}$ \\
\hline
\end{tabular}

Note: Standard errors in parentheses. $* p \leq 0.05 ; * * p \leq 0.10$ 
Figure 1: High School Sports Participation Rates by Gender, 1971-1980

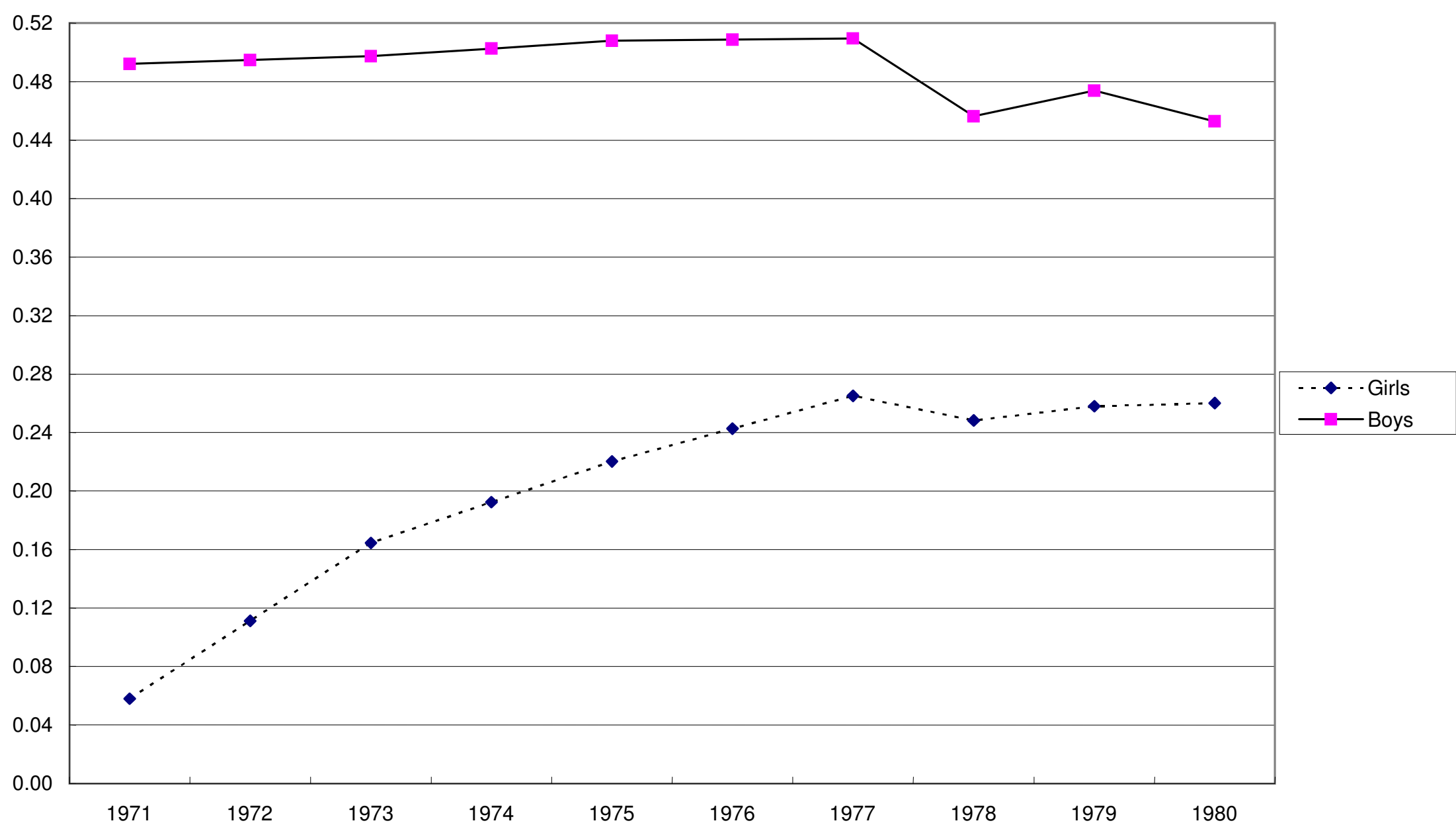

Notes: The figure is based on unweighted high school sports participation rates for each state from 1971-1980. Due to the missing values of high school sports participation rates in some states, we adjusted for state effects. High school sports participation comes from the National Federation of State High School Associations (NFSHSA) and the population data come from the 1970 and 1980 US Censuses. 